\title{
Coplanarity Condition for Photogrammetric Simultaneous and Self Calibration Block Adjustments
}

\author{
Prof. Dr. Khalid L. A. El-Ashmawy \\ Department of Civil Engineering \\ College of Engineering and Islamic Architecture \\ Umm Al-Qura University \\ Makkah \\ Saudi Arabia
}

\begin{abstract}
The well-known collinearity equations are widely employed for the determination of object space coordinates of points during the aerial and close-range photogrammetry applications. On the other hand, the coplanarity equation is applied for analytical relative orientation which is essential for sequential block adjustment procedure.

This paper concentrates on deriving mathematical formulation based on coplanarity condition. Softwares utilizing the derived mathematical models have been developed and tested using mathematical photogrammetric data.

The effects of random and lens distortion errors on simultaneous and self-calibration block adjustments using the derived mathematical models and collinearity equations have been studied.

It was found that the derived mathematical models compensate for the lens distortion errors better than collinearity equations. Furthermore, the accuracy of the results of self-calibration block adjustment using the coplanarity equation is slightly better than those obtained by collinearity equations.
\end{abstract}

Key Words: Collinearity Equations, Coplanarity Equation, Simultaneous Block Adjustments, Self Calibration Block Adjustments, Accuracy Analysis.

\section{INTRODUCTION}

Analytical photogrammetry consists of mathematical modeling of the relationship between different systems ( e.g. photo and ground, photo and model, model and ground). To reach a solution, one may have to use a set of condition equations to establish first the relationship between the observed values and the unknown parameters. The condition equations most commonly used are: (i) Collinearity condition and (ii) coplanarity condition. Each condition equation has specific functions, scopes and limitations. The choice of the condition may, therefore, lead to different approaches to the solution of any specific problem.

The condition of collinearity (Figure 1) is that an object point (P), its image point (p) and the perspective centre (O), must lie along the same line. Mathematically, this condition is expressed as [1]:

$$
\left.\begin{array}{c}
x_{p}=-f \frac{\left(X_{P}-X_{O}\right) m_{11}+\left(Y_{P}-Y_{O}\right) m_{12}+\left(Z_{P}-Z_{O}\right) m_{13}}{\left(X_{P}-X_{O}\right) m_{31}+\left(Y_{P}-Y_{O}\right) m_{32}+\left(Z_{P}-Z_{O}\right) m_{33}} \\
y_{p}=-f \frac{\left(X_{P}-X_{O}\right) m_{21}+\left(Y_{P}-Y_{O}\right) m_{22}+\left(Z_{P}-Z_{O}\right) m_{23}}{\left(X_{P}-X_{O}\right) m_{31}+\left(Y_{P}-Y_{O}\right) m_{32}+\left(Z_{P}-Z_{O}\right) m_{33}}
\end{array}\right\}
$$

where $x_{p}, y_{p}$ are the corrected photo coordinates, $X_{P}, Y_{P}, Z_{P}$ are the object space coordinates of point $\mathrm{P}, X_{O}, Y_{O}, Z_{O}$ are the object space coordinates of the perspective centre $\mathrm{O}, \mathrm{f}$ is the calibrated focal length of the camera, and $m_{i j}(\mathrm{i}=1,2,3 ; \mathrm{j}=1,2,3)$ are the elements of the orientation matrix (M) of the photograph. 
The coplanarity condition (Figure 1) implies that the two perspective centres, any object point and the corresponding image points on the two photographs of the stereo-pair, must all lie in a common plane. The coplanarity condition can be expressed as [1]:

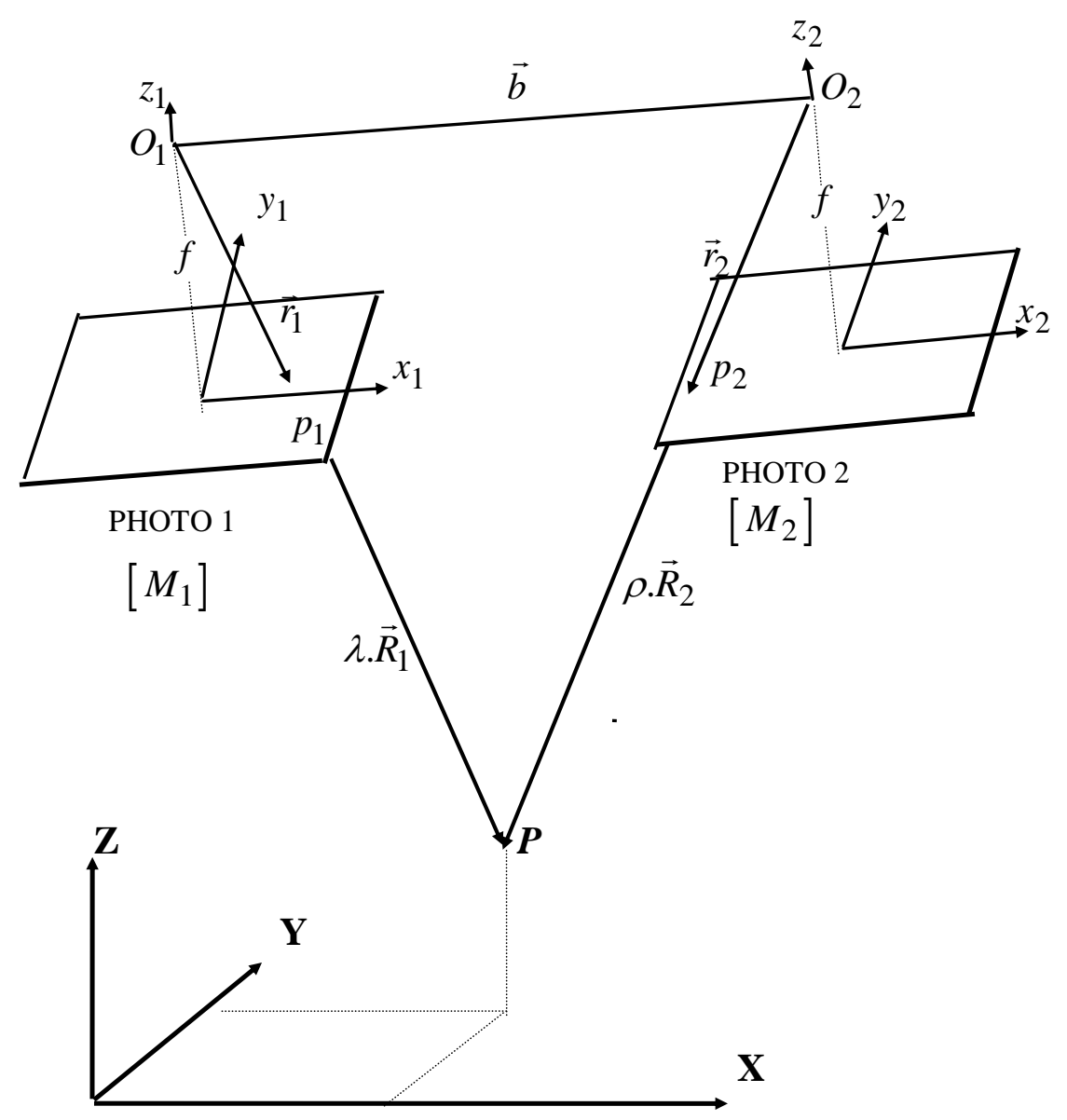

Figure 1. Collinearity \& Coplanarity Conditions

$$
F_{i}=\left|\begin{array}{ccc}
b_{X} & b_{Y} & b_{Z} \\
X_{1} & Y_{1} & Z_{1} \\
X_{2} & Y_{2} & Z_{2}
\end{array}\right|=0
$$

where $b_{X}, b_{Y}, b_{Z}$ are the components of the air base vector $\vec{b}$, and $X_{1}, Y_{1}, Z_{1}$ and $X_{2}, Y_{2}, Z_{2}$ are the components of the vectors $\vec{R}_{1}$ (from $O_{1}$ to $P$ ) and $\vec{R}_{2}$ (from $O_{2}$ to $P$ ) respectively.

The components of the vectors $\vec{b}, \vec{R}_{1}$ and $\vec{R}_{2}$ can be expressed as follows:

$$
\vec{b}=\left[\begin{array}{c}
b_{X} \\
b_{Y} \\
b_{Z}
\end{array}\right]=\left[\begin{array}{c}
X_{O 2}-X_{O 1} \\
Y_{O 2}-Y_{O 1} \\
Z_{O 2}-Z_{O 1}
\end{array}\right]
$$




$$
\vec{R}_{1}=\left[\begin{array}{c}
X_{1} \\
Y_{1} \\
Z_{1}
\end{array}\right]=\lambda \cdot M_{1}^{T}\left[\begin{array}{c}
x_{1} \\
y_{1} \\
-f
\end{array}\right]=\lambda \cdot M_{1}^{T} \cdot \vec{r}_{1}
$$

and

$$
\vec{R}_{2}=\left[\begin{array}{c}
X_{2} \\
Y_{2} \\
Z_{2}
\end{array}\right]=\rho \cdot M_{2}^{T}\left[\begin{array}{c}
x_{2} \\
y_{2} \\
-f
\end{array}\right]=\rho \cdot M_{2}^{T} \cdot \vec{r}_{2}
$$

where $\lambda$ and $\rho$ are scale factors of the corresponding location vectors $\vec{r}_{1}$ and $\vec{r}_{2}$ within the camera space.

The collinearity equations are basic to all procedures in photogrammetry such as simultaneous block adjustment [1],[2],[3], self-calibration block adjustment [4],[5], processing space photography [6],[7],[8], and space resection and intersection [1],[2]. On the other hand, the coplanarity equation is usually employed for the process of analytical relative orientation which is essential for block triangulation with independent models [1],[4],[9],[10],[11].

Since the coordinates of points in object space are not included in coplanarity equation (Equation (2)), the coplanarity equation by itself is not sufficient for a complete solution of any phototriangulation problem [1].

The aims of this paper are:

- Derivation of a mathematical formulation based on coplanarity condition for block adjustment;

- Investigation of the accuracy of the derived mathematical formulation; and

- Comparison between the results of the derived mathematical formulation with the results of collinearity equations for block adjustment.

\section{THE MATHEMATICAL FORMULATION}

The coplanarity condition depends on the intersection of pairs of rays, $\vec{R}_{1}$ (from $O_{1}$ to $P$ ) and $\vec{R}_{2}$ (from $O_{2}$ to $P$ ), on the object space point P. It is quite possible that the rays fail to intersect on P, giving thereby residual parallaxes (Figure 2). The parallax (vector $\vec{D}$ ) is defined as the three dimensional disparity between the left and right rays projected from conjugate image points on the left and right photographs.

By convention, parallax is defined as left-right, so the vector points from the right ray to the left ray. The vector of parallax can be derived from the standard vector equation [12] as:

$$
\vec{b}+\rho \cdot \vec{R}_{2}+\vec{D}-\lambda \cdot \vec{R}_{1}=0
$$

which leads to:

$$
\vec{D}=\lambda \cdot \vec{R}_{1}-\rho \cdot \vec{R}_{2}-\vec{b}
$$

The measurement in the object space (vector $\vec{P}$ ) is defined as the mean location of the left and right rays, which is also the mid-point of the parallax vector [1]. The vectors $\vec{S}$ and $\vec{P}$ can be derived as:

$$
\begin{aligned}
& \vec{S}=\vec{b}+\rho \cdot \vec{R}_{2}+0.5 * \vec{D} \\
& \vec{P}=\vec{O}_{1}+\vec{S}
\end{aligned}
$$

Substituting Equations (7) and (8) into (9),

$$
\vec{P}=\vec{O}_{1}+0.5 *\left(\vec{b}+\lambda \cdot \vec{R}_{1}+\rho \cdot \vec{R}_{2}\right)
$$


The two scale factors $\lambda$ and $\rho$ are nuisance parameters and can be derived by selecting a solution such that the $\mathrm{x}$ and $\mathrm{z}$ parallaxes disappear. Using the first and third scalar equations from Equation (7):

$$
\left.\begin{array}{l}
\lambda=\left(b_{X} \cdot Z_{2}-b_{Z} \cdot X_{2}\right) /\left(b_{X} \cdot Z_{1}-b_{Z} \cdot X_{1}\right) \\
\rho=\left(b_{X} \cdot Z_{1}-b_{Z} \cdot X_{1}\right) /\left(b_{X} \cdot Z_{1}-b_{Z} \cdot X_{1}\right)
\end{array}\right\}
$$

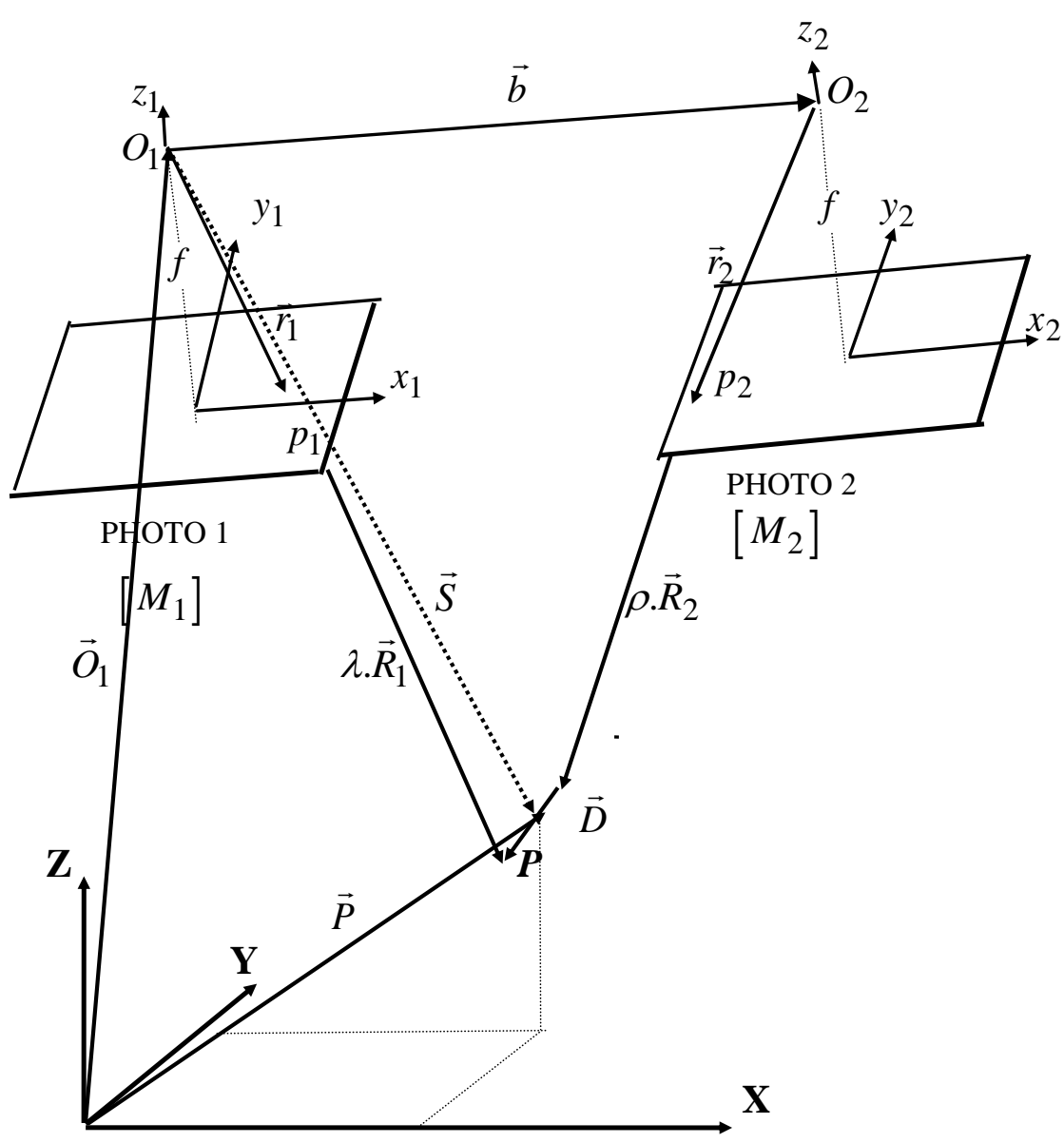

Figure 2. Coplanarity Condition and Parallax

\subsection{The Mathematical Model for Simultaneous Block Adjustment}

From Equations (7) and (10), the mathematical model consists of four scalar equations as follows:

$$
\left.\begin{array}{l}
X_{P}-\left(X_{O_{1}}+0.5 *\left(b_{X}+\lambda . X_{1}+\rho . X_{2}\right)\right)=0.0 \\
Y_{P}-\left(Y_{O_{1}}+0.5 *\left(b_{Y}+\lambda . Y_{1}+\rho . Y_{2}\right)\right)=0.0 \\
Z_{P}-\left(Z_{O_{1}}+0.5 *\left(b_{Z}+\lambda . Z_{1}+\rho . Z_{2}\right)\right)=0.0 \\
D_{Y}=\lambda . X_{1}-\rho . X_{2}-b_{Y}=0.0
\end{array}\right\}
$$

The linearised form of Equation (12), for least squares method solution, can be given by:

$$
A \cdot V+B . \Delta=\varepsilon
$$


where:

$\Delta \quad$ is the correction vector to the current values set for the unknowns ( the camera exterior orientation parameters of the left and right photos, object space coordinates of the new points) in the iterative solution;

$A$ is the matrix of the partial derivatives of Equation (12) with respect to the observations (corrected photo coordinates on the left and right photos of the same object point);

$B \quad$ is the matrix of the partial derivatives of Equation (12) with respect to the unknowns;

$V \quad$ is the residual vector, i.e., the correction vector to the observations; and

$\varepsilon \quad$ is the discrepancy vector.

The principle of the least squares method requires the minimizing of the quadratic form $V^{t} . W . V$, where $\mathrm{W}$ is the weight matrix whose elements are the weights associated with each of the observations. The least squares solution of an equation similar to Equation (13) can be given as [13],[14]:

$$
\Delta=N^{-1} \cdot C
$$

where

$$
\left.\begin{array}{l}
N=B^{t} \cdot Q_{e}^{-1} \cdot B \\
C=B^{t} \cdot Q_{e}^{-1} \cdot \varepsilon \\
Q_{e}=A \cdot W^{-1} \cdot A^{t}
\end{array}\right\}
$$

\subsection{The Mathematical Model for Simultaneous Block Adjustment With Constraints}

Constraints are suggested to consider supplemental observation equations [1] arising from a priori knowledge regarding the object space coordinates of the control points in Equation (13). Such supplemental equations can be written as follows:

$$
V^{c}-\Delta^{c}=\varepsilon^{c}
$$

where:

$\Delta^{c} \quad$ is the vector of observational corrections to the object space coordinates of the control points; and

$\varepsilon^{c} \quad$ is the discrepancy vector, between observed values and current (in iterative solution) values of the object space coordinates of the control points.

Observation equations can be obtained by merging Equations (13) and (16) as:

$$
\left.\begin{array}{l}
A . V+B . \Delta=\varepsilon \\
V^{c}-\Delta^{c}=\varepsilon^{c}
\end{array}\right\}
$$

in which $\Delta$ is the correction vector to the current values set for the unknowns which are the camera exterior orientation parameters of the left and right photos, object space coordinates of all points. The other matrices are as defined earlier.

\subsection{The Mathematical Model for Self Calibration Block Adjustment}

In Equation (12), the observations are the left and right photo coordinates on an object point. Considering the case of camera calibration, the $x_{p} \& y_{p}$ corrected photo coordinates can be obtained by [1]: 


$$
\left.\begin{array}{l}
x_{p}=\bar{x}_{p}-x_{o}+F(k) \cdot \bar{x}_{p} / r+\Delta x(p) \\
y_{p}=\bar{y}_{p}-y_{o}+F(k) \cdot \bar{y}_{p} / r+\Delta y(p)
\end{array}\right\}
$$

in which

$$
\begin{aligned}
& x_{p}, y_{p} \text { are the corrected photo coordinates; } \\
& \bar{x}_{p}, \bar{y}_{p} \text { are the observed photo coordinates; } \\
& x_{o}, y_{o} \text { are the photo coordinates of the principal point; } \\
& r^{2}=\bar{x}_{p}^{2}+\bar{y}_{p}^{2} \\
& \begin{aligned}
F(k)=K_{1} r^{3}+K_{2} r^{5}+K_{3} r^{7} \\
\quad=\text { function of symmetrical radial lens distortion; }
\end{aligned}
\end{aligned}
$$

$\Delta x(p), \Delta y(p)$ are the decentering lens distortion corrections for $\mathrm{x}$ and $\mathrm{y}$ photo coordinates, and can be obtained by:

$$
\left.\begin{array}{l}
\Delta x(p)=P_{1}\left(r^{2}+2 \bar{x}_{p}^{2}\right)+P_{2}\left(2 \bar{x}_{p} \bar{y}_{p}\right) \\
\Delta y(p)=P_{2}\left(r^{2}+2 \bar{y}_{p}^{2}\right)+P_{1}\left(2 \bar{x}_{p} \bar{y}_{p}\right)
\end{array}\right\}
$$

where $P_{1}, P_{2}$ are correction coefficients for decentering lens distortion.

The observation equations form in this case is similar to Equation (13) where $\Delta$ is the correction vector to the current values set for the unknowns which are the $x_{o}, y_{o} f, K_{1}, K_{2}, K_{3}, P_{1}, P_{2}$, camera exterior orientation parameters of the left and right photos, object space coordinates of new points, and the other matrices are as defined earlier.

\subsection{The Mathematical Model for Self Calibration Block Adjustment With Constraints}

As has been mentioned earlier, constraints are added regarding a priori knowledge of the object space coordinates of the control points in Equation (13) and the observation equations form becomes similar to Equation (17) in which $\Delta_{\text {is }}$ the correction vector to the current values set for the unknowns which are the $x_{o}, y_{0} f, K_{1}, K_{2}, K_{3}, P_{1}, P_{2}$, camera exterior orientation parameters of the left and right photos, object space coordinates of all points, and the other matrices are as defined earlier.

\section{COMPARING THE RESULTS OF THE DERIVED MATHEMATICAL MODELS}

Collinearity equations (Equation (1)) are used for comparing the results of the derived mathematical models for block adjustment.

\subsection{The Mathematical Model for Bundle Block Adjustment}

The linearized form of Equation (1), for least squares method solution, can be given by:

$$
\left.\begin{array}{l}
V+B . \Delta=\varepsilon \\
V^{c}-\Delta^{c}=\varepsilon^{c}
\end{array}\right\}
$$

where: 
$\Delta \quad$ is the correction vector to the current values set for the unknowns ( the camera exterior orientation parameters, object space coordinates of all points) in the iterative solution;

$B \quad$ is the matrix of the partial derivatives of Equation (1) with respect to the unknowns;

$V \quad$ is the residual vector, i.e., the correction vector to the observations; and the other matrices are as defined earlier.

The principle of the least squares method requires the minimizing of the quadratic form $V^{t} . W . V$, where $\mathrm{W}$ is the weight matrix whose elements are the weights associated with each of the observations. The least squares solution of an equation similar to Equation (21) can be given as [13],[14]:

$$
\Delta=N^{-1} \cdot C
$$

where

$$
N=B^{t} \cdot W^{-1} \cdot B \text { and } C=B^{t} \cdot W^{-1} \cdot \varepsilon
$$

Equations (1) and (21) are the mathematical foundation for developing PHOTOMAP software [4].

\section{3-2 The Mathematical Model for Self Calibration Block Adjustment}

In Equation (1), the observations are the photo coordinates of an object point. Considering the case of camera calibration, the $x_{p} \& y_{p}$ corrected photo coordinates can be obtained by Equation (18) as explained earlier.

The observation equations form in this case is similar to Equation (21) where $\Delta$ is the correction vector to the current values set for the unknowns which are the $x_{o}, y_{a} f, K_{1}, K_{2}, K_{3}, P_{1}, P_{2}$, camera exterior orientation parameters of the photo, object space coordinates of all points; and the other matrices are as defined earlier.

\section{DEVELOPING THE NECESSARY SOFTWARES}

The current research includes the development of five softwares. The list of these softwares and their main tasks are tabulated in Table 1.

Table 1. The Developed Softwares and Their Main Tasks

\begin{tabular}{|l|l|}
\hline \multicolumn{1}{|c|}{ SOFTWARE } & \multicolumn{1}{c|}{ MAIN TASK } \\
\hline Cop_No_Consts & $\begin{array}{l}\text { Simultaneous block adjustment without constraints } \\
\text { (Using coplanarity equations) }\end{array}$ \\
\hline Cop_Consts & $\begin{array}{l}\text { Simultaneous block adjustment with constraints } \\
\text { (Using coplanarity equations) }\end{array}$ \\
\hline Cop_Cal_No_Consts & $\begin{array}{l}\text { Self calibration block adjustment without constraints } \\
\text { (Using coplanarity equations) }\end{array}$ \\
\hline Cop_Cal_Consts & $\begin{array}{l}\text { Self calibration block adjustment with constraints } \\
\text { (Using coplanarity equations) }\end{array}$ \\
\hline Col_Cal_Consts & $\begin{array}{l}\text { Self calibration block adjustment with constraints } \\
\text { (Using collinearity equations) }\end{array}$ \\
\hline
\end{tabular}

These softwares provide an access to major computational phases of analytical block triangulation. The main functions of the developed softwares are: 
a. Data preparation: It performs the necessary tasks for preparing the data to start block adjustment such as:

- Testing the geometry of the input data: It includes testing the availability of each point in at least two photographs and giving complete information about the block adjustment parameters such as number of observations and unknowns, degree of freedom, etc.

- Two dimensional affine transformation to transform the instrumental photo coordinates of control, pass and tie points to the fiducial marks coordinate system.

- Refinement of photo coordinates: Corrections for principal point displacement, lens distortion, atmospheric refraction and earth curvature, if applicable, are to be applied to the photo coordinates.

- Computation of the initial values of unknowns: It includes the computation of the initial values of camera exterior orientation parameters and/or object space coordinates of points [4] which are essential for starting the iterative solution.

b. Iterative least squares method solution for performing the specified task as shown in Table 1. This includes the computations of the adjusted values of unknowns, depending on the specified task, residuals of photo and object space coordinates of control points, if any, and variance of unit weight.

c. Computation of statistical data: It includes the computation of the necessary data for statistical analysis and error detection [4] such as variance of unit weight, cofactor and covariance matrices for unknowns, depending on the specified task, adjusted photo coordinates and their cofactor matrix, residuals of photo coordinates, dimensions of error ellipses, etc.

For automatic processing and representation of the data and results, the softwares utilize efficient techniques of Data Structuring [15], Random File Access and Dynamic Memory Allocations [16]. The softwares have been designed to make use of efficient user interfaces (window-driven) for facilitating its execution to the user [17].

\section{TESTING THE SYSTEM ERROR FOR THE DEVELOPED SOFTWARES}

Simultaneous and self calibration block adjustments involve extensive computations and the various steps of which are subjected to computational system error. System error consists of two parts. The first part of this error is due to rounding off of values during intermediate computations. This part of error may be minimised by using double precision computations as far as possible. The second part of the system error occurs due to truncation of higher order terms while forming the linearised observation equations from the non linear condition equations.

The mathematical photogrammetric data can be advantageously used for testing of photogrammetric methodologies and systems since in this case error free input data and end results are both known [4].

MATHP software [4] has been used for generating the necessary mathematical blocks of photographs. Out of the various mathematical photogrammetric blocks generated, the block having following specifications was used for testing the developed softwares:
a. Photograph scale
b. Camera Format
c. Camera focal length
d. Longitudinal and Lateral overlaps
e. Terrain configuration

$: 1: 1$

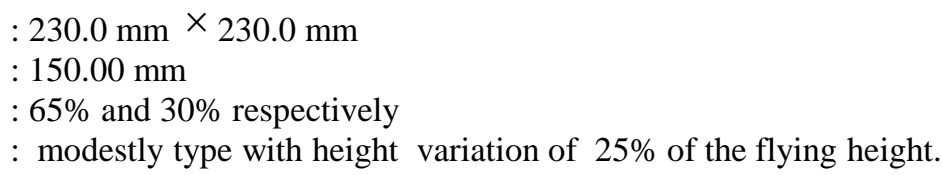

To reduce the effect of the number and location of the control points during the testing phase of the system error, suitable distribution and number of control points have been adopted [4]. The block size was 5 strips each of five photographs. In this case, the block contained 55 and 110 control and check points respectively.

In order to ascertain the accuracy of the results, the root mean square error (RMSE) was computed using the well known formulation:

$$
R M S E=\sqrt{\sum_{i=1}^{n}(\text { known or actual value }- \text { computed value })_{i}^{2} / n}
$$


For each software, the RMSE values for camera exterior orientation parameters and ground coordinates of check points for this testing phase have been obtained. The results showed that the maximum system error is $0.0002 \mu \mathrm{m}$, at photo scale $1: 1$, for the ground coordinates of check points which is negligible.

From above, it is seen that the developed softwares are free from system error and that they are functional.

\section{STUDYING THE EFFECTS OF ERRORS ON THE RESULTS OF BLOCK ADJUSTMENT}

The present work concentrates on studying the effect of the random and lens distortion errors on the results of block adjustment.

\subsection{Studying The Effect of The Random Errors}

The effect of the random errors was tested by numerical simulation as following:

- Generating error free photogrammetric data of blocks of different sizes using MATHP software.

- Developing a special error generator to generate normally distributed error(s) with arbitrary mean(s) and standard deviation(s) as presented in the Appendix. The obtained errors were then applied to the error free photo coordinates and ground coordinates of control points of the generated blocks. The configurations of the used blocks are shown in Table 2.

- Finally, simultaneous block adjustment using the derived mathematical models and collinearity equations was performed to adjust the available blocks and the results, in the form of standard deviation of unit weight $\left(\hat{\sigma}_{o}\right)$ and RMSE values at control and check points, were obtained and tabulated in Table 3.

Table 2. The Configurations for Mathematical Photogrammetric Blocks of Photographs

\begin{tabular}{|c|c|c|c|c|c|c|c|c|c|c|c|c|c|c|c|c|c|c|}
\hline \multirow{4}{*}{ 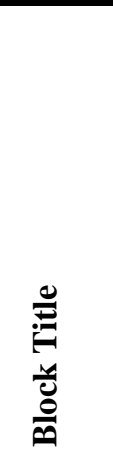 } & \multicolumn{3}{|c|}{ Block Size } & \multicolumn{2}{|c|}{$\begin{array}{l}\text { Ground } \\
\text { Points }\end{array}$} & \multirow{4}{*}{ 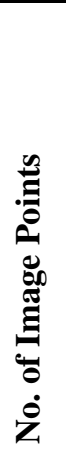 } & \multicolumn{12}{|c|}{ Random Errors $(\mu m)^{*}$} \\
\hline & \multirow{3}{*}{ 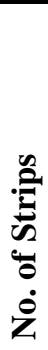 } & \multirow{3}{*}{ 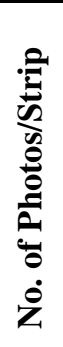 } & \multirow{3}{*}{$\begin{array}{l}\frac{y}{0} \\
\frac{0}{0} \\
\overline{\tilde{o}} \\
\frac{0}{0} \\
\frac{8}{2} \\
\frac{0}{0} \\
\dot{0}\end{array}$} & \multirow{3}{*}{ 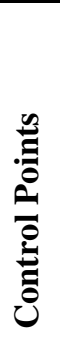 } & \multirow{3}{*}{ 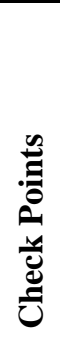 } & & \multicolumn{3}{|c|}{$\begin{array}{c}\text { Photo } \\
\text { Coordinates }\end{array}$} & \multicolumn{9}{|c|}{ Ground Coordinates of Control Points } \\
\hline & & & & & & & & & & \multicolumn{3}{|c|}{$\mathbf{X}$} & \multicolumn{3}{|c|}{$\mathbf{Y}$} & \multicolumn{3}{|c|}{$\mathbf{Z}$} \\
\hline & & & & & & & 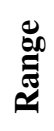 & 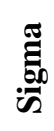 & $\sum^{\tilde{E}}$ & 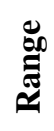 & 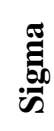 & 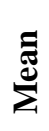 & 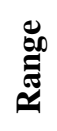 & 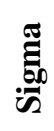 & $\sum^{\mathbb{E}}$ & 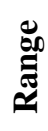 & 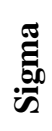 & $\stackrel{\Xi}{\tilde{E}}$ \\
\hline 1Model & - & N & $\mathrm{N}$ & 6 & $\simeq$ & e & $\frac{\infty}{1}+$ & $\stackrel{f}{\tilde{f}}$ & $\stackrel{0}{0}$ & $\frac{m}{+}$ & $\frac{0}{4}$ & $\stackrel{0}{0}$ & $\frac{+}{+1}$ & $\stackrel{\infty}{i}$ & $\stackrel{0}{0}$ & $\frac{n}{x}$ & $\stackrel{n}{n}$ & $\stackrel{0}{0}$ \\
\hline 1Strip & - & $n$ & $n$ & 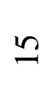 & e & 그 & $\frac{9}{1}$ & $\stackrel{\grave{n}}{m}$ & $\stackrel{0}{0}$ & $\frac{\infty}{1}$ & $\bar{i}$ & $\stackrel{n}{n}$ & $\frac{n}{1}$ & $\begin{array}{l}+ \\
\infty \\
i\end{array}$ & $\stackrel{ヘ}{0}$ & $\frac{T}{+}$ & $\begin{array}{l}\infty \\
\infty \\
\dot{m}\end{array}$ & $\stackrel{0}{0}$ \\
\hline 2Strips & N & $n$ & $\stackrel{0}{-}$ & 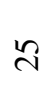 & $\stackrel{\circ}{n}$ & 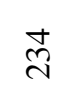 & $\frac{7}{7}$ & $\bar{n}$ & $\stackrel{0}{0}$ & $\frac{n}{x}$ & 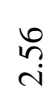 & $\frac{0}{0}$ & $\frac{T}{1}$ & $\underset{\text { ç }}{\text { m. }}$ & $\frac{1}{\square}$ & $\frac{\infty}{1}$ & $\begin{array}{l}\infty \\
\infty \\
\dot{m}\end{array}$ & $\stackrel{\infty}{\circ}$ \\
\hline 3Strips & $m$ & $n$ & $\mathfrak{n}$ & $m$ & $\stackrel{R}{R}$ & $\bar{n}$ & $\frac{7}{7}$ & $\tilde{n}$ & $\stackrel{0}{0}$ & $\frac{T}{+}$ & $\stackrel{\hat{r}}{i}$ & $\stackrel{\circ}{\circ}$ & $\frac{T}{+}$ & $\tilde{a}$ & $\stackrel{\circ}{\circ}$ & $\stackrel{\infty}{\frac{\infty}{+}}$ & $\begin{array}{l}\infty \\
n \\
n\end{array}$ & $\frac{1}{0}$ \\
\hline 4Strips & $\nabla$ & $n$ & 요 & $\stackrel{\wp}{q}$ & \& & 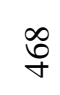 & $\frac{7}{\frac{1}{7}}$ & 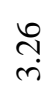 & $\stackrel{0}{0}$ & $\frac{0}{1}$ & $\stackrel{n}{n}$ & $\frac{m}{p}$ & $\frac{T}{x}$ & $\frac{a}{m}$ & $\begin{array}{l}\dot{0} \\
\dot{0}\end{array}$ & $\frac{\infty}{1}$ & $\stackrel{\text { +o }}{\dot{m}}$ & $\begin{array}{l}0 \\
0 \\
0\end{array}$ \\
\hline 5Strips & $n$ & $n$ & 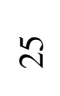 & $n$ & $\stackrel{\circ}{=}$ & $\begin{array}{l}n \\
\infty \\
\infty\end{array}$ & $\frac{7}{7}$ & $\stackrel{\circ}{\sim}$ & $\stackrel{0}{0}$ & $\frac{T}{+}$ & $\frac{n}{i}$ & $\stackrel{\Xi}{0}$ & $\frac{T}{+}$ & $\stackrel{\circ}{m}$ & 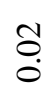 & $\stackrel{\infty}{\frac{1}{+}}$ & $\stackrel{⿱ 亠 乂}{\dot{m}}$ & 志 \\
\hline
\end{tabular}


From Table 3, the following conclusions can be obtained:

- The derived mathematical models are suitable for simultaneous block adjustment for a block of photographs of any size.

- There is no significant difference between the a posterior standard deviation $\left(\hat{\sigma}_{o}\right)$ and the a priori standard deviation $\left(\sigma_{o}\right)$ and hence that the correct simulation assumptions and block adjustment have been achieved.

- Adding constraints has significant effect on improving the accuracy of the obtained results.

- The results of simultaneous block adjustment using coplanarity equations with constraints and using collinearity equations are similar.

Table 3. The Results of Simultaneous Block Adjustment (Case of Random Errors Only)

\begin{tabular}{|c|c|c|c|c|c|c|c|c|c|}
\hline \multirow{3}{*}{ 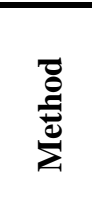 } & \multirow{3}{*}{$\begin{array}{l}\text { Block } \\
\text { Title }\end{array}$} & \multirow[b]{3}{*}{$\sigma_{o}$} & \multirow[b]{3}{*}{$\hat{\sigma}_{o}$} & \multicolumn{6}{|c|}{ RMSE Values for Ground Coordinates $(\mu m)^{*}$} \\
\hline & & & & \multicolumn{3}{|c|}{ Control Points } & \multicolumn{3}{|c|}{ Check Points } \\
\hline & & & & $\mathbf{X}$ & $\mathbf{Y}$ & $\mathbf{Z}$ & $\mathbf{X}$ & $\mathbf{Y}$ & $\mathbf{Z}$ \\
\hline 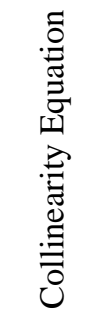 & $\begin{array}{l}\text { 1Model } \\
\text { 1Strip } \\
\text { 2Strip } \\
\text { 3Strip } \\
\text { 4Strip } \\
\text { 5Strip }\end{array}$ & $\begin{array}{l}1.00 \\
1.00 \\
1.00 \\
1.00 \\
1.00 \\
1.00\end{array}$ & $\begin{array}{l}0.94 \\
1.04 \\
1.00 \\
1.03 \\
1.01 \\
0.98\end{array}$ & $\begin{array}{l}1.57 \\
1.81 \\
1.44 \\
1.83 \\
1.79 \\
1.72\end{array}$ & $\begin{array}{l}0.99 \\
1.46 \\
2.29 \\
2.31 \\
1.77 \\
2.23\end{array}$ & $\begin{array}{l}3.39 \\
2.08 \\
3.06 \\
2.81 \\
2.31 \\
2.29\end{array}$ & $\begin{array}{l}4.55 \\
5.00 \\
2.83 \\
2.39 \\
2.61 \\
2.52\end{array}$ & $\begin{array}{l}5.52 \\
5.05 \\
3.60 \\
3.42 \\
2.88 \\
3.01\end{array}$ & $\begin{array}{l}7.94 \\
7.68 \\
5.88 \\
6.07 \\
4.96 \\
5.61\end{array}$ \\
\hline 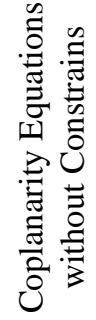 & $\begin{array}{l}\text { 1Model } \\
\text { 1Strip } \\
\text { 2Strip } \\
\text { 3Strip } \\
\text { 4Strip } \\
\text { 5Strip }\end{array}$ & $\begin{array}{l}1.00 \\
1.00 \\
1.00 \\
1.00 \\
1.00 \\
1.00\end{array}$ & $\begin{array}{l}1.10 \\
1.07 \\
0.97 \\
1.04 \\
1.01 \\
1.01\end{array}$ & $\begin{array}{l}-- \\
-- \\
-- \\
-- \\
-- \\
--\end{array}$ & $\begin{array}{l}-- \\
-- \\
-- \\
-- \\
-- \\
--\end{array}$ & $\begin{array}{l}-- \\
-- \\
-- \\
-- \\
-- \\
--\end{array}$ & $\begin{array}{l}4.58 \\
5.08 \\
3.04 \\
2.37 \\
2.61 \\
2.64\end{array}$ & $\begin{array}{l}5.58 \\
5.52 \\
3.46 \\
3.39 \\
2.90 \\
3.12\end{array}$ & $\begin{array}{l}8.64 \\
7.97 \\
5.93 \\
6.30 \\
5.07 \\
6.04\end{array}$ \\
\hline 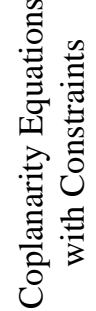 & $\begin{array}{l}\text { 1Model } \\
\text { 1Strip } \\
\text { 2Strip } \\
\text { 3Strip } \\
\text { 4Strip } \\
\text { 5Strip }\end{array}$ & $\begin{array}{l}1.00 \\
1.00 \\
1.00 \\
1.00 \\
1.00 \\
1.00\end{array}$ & $\begin{array}{l}0.94 \\
1.04 \\
1.00 \\
1.03 \\
1.01 \\
0.98\end{array}$ & $\begin{array}{l}1.57 \\
1.81 \\
1.44 \\
1.83 \\
1.79 \\
1.72\end{array}$ & $\begin{array}{l}0.99 \\
1.46 \\
2.29 \\
2.31 \\
1.77 \\
2.23\end{array}$ & $\begin{array}{l}3.39 \\
2.08 \\
3.06 \\
2.81 \\
2.31 \\
2.29\end{array}$ & $\begin{array}{l}4.55 \\
5.00 \\
2.83 \\
2.39 \\
2.61 \\
2.52\end{array}$ & $\begin{array}{l}5.52 \\
5.05 \\
3.60 \\
3.42 \\
2.88 \\
3.01\end{array}$ & $\begin{array}{l}7.94 \\
7.68 \\
5.88 \\
6.07 \\
4.96 \\
5.61\end{array}$ \\
\hline
\end{tabular}

* Values at Photo Scale 1:1

\subsection{Studying The Effect of The Lens Distortion Errors}

As has been mentioned, lens distortion consists of two components: symmetric lens distortion and asymmetric lens distortion. The adopted mathematical model for symmetric lens distortion is given by Equation (19). The asymmetrical lens distortion is due to the lenses decentering and its modeling is given by Equation (20). The lens distortion errors were introduced to the blocks of mathematical photographs as follows:

- Generating error free photogrammetric data of blocks of different sizes using MATHP software.

- Assigning values for the lens distortion coefficients and generating errors in the range of $50 \mu m$ using Equations (19) and (20).

- Adding the generated errors to the error free photo coordinates 
International Journal of Advances in Scientific Research and Engineering (ijasre), Vol 7 (2), February -2021

The results of self calibration block adjustments are shown in Table 4.

\subsection{Studying the effect of random and lens distortion errors}

In this case, error free photogrammetric data of blocks of different sizes using MATHP software were generated, and random and lens distortion errors were generated and applied to the error free photo coordinates and ground coordinates of control points of the generated blocks as explained earlier.

Table 5 illustrates the results of self calibration block adjustments, for this case.

Table 4. The Results of Self Calibration Block Adjustment (Case of Lens Distortion Errors)

\begin{tabular}{|c|c|c|c|c|c|c|c|}
\hline \multirow{3}{*}{ 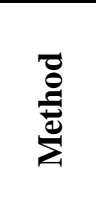 } & \multirow{3}{*}{$\begin{array}{c}\text { Block } \\
\text { Title }\end{array}$} & \multicolumn{6}{|c|}{ RMSE Values for Ground Coordinates $(\mu \mathrm{m})^{*}$} \\
\hline & & \multicolumn{3}{|c|}{ Control Points } & \multicolumn{3}{|c|}{ Check Points } \\
\hline & & $\mathbf{X}$ & $\mathbf{Y}$ & $\mathbf{Z}$ & $\mathbf{X}$ & $\mathbf{Y}$ & $\mathbf{Z}$ \\
\hline 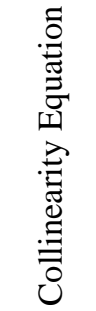 & $\begin{array}{l}\text { 1Model } \\
\text { 1Strip } \\
\text { 2Strip } \\
\text { 3Strip } \\
\text { 4Strip } \\
\text { 5Strip }\end{array}$ & $\begin{array}{l}0.003 \\
0.011 \\
0.011 \\
0.012 \\
0.012 \\
0.011\end{array}$ & $\begin{array}{l}0.006 \\
0.009 \\
0.009 \\
0.009 \\
0.009 \\
0.009\end{array}$ & $\begin{array}{l}0.005 \\
0.012 \\
0.012 \\
0.012 \\
0.012 \\
0.012\end{array}$ & $\begin{array}{l}0.046 \\
0.030 \\
0.027 \\
0.024 \\
0.023 \\
0.023\end{array}$ & $\begin{array}{l}0.052 \\
0.030 \\
0.028 \\
0.025 \\
0.024 \\
0.023\end{array}$ & $\begin{array}{l}0.093 \\
0.056 \\
0.051 \\
0.049 \\
0.045 \\
0.046\end{array}$ \\
\hline 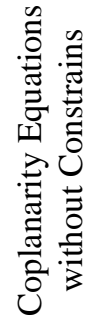 & $\begin{array}{l}\text { 1Model } \\
\text { 1Strip } \\
\text { 2Strip } \\
\text { 3Strip } \\
\text { 4Strip } \\
\text { 5Strip }\end{array}$ & $\begin{array}{l}-- \\
-- \\
-- \\
-- \\
-- \\
--\end{array}$ & $\begin{array}{l}-- \\
-- \\
-- \\
-- \\
-- \\
--\end{array}$ & $\begin{array}{l}-- \\
-- \\
-- \\
-- \\
-- \\
--\end{array}$ & $\begin{array}{l}0.044 \\
0.029 \\
0.027 \\
0.024 \\
0.023 \\
0.023\end{array}$ & $\begin{array}{l}0.052 \\
0.029 \\
0.026 \\
0.025 \\
0.023 \\
0.022\end{array}$ & $\begin{array}{l}0.093 \\
0.054 \\
0.050 \\
0.047 \\
0.045 \\
0.046\end{array}$ \\
\hline 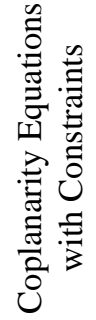 & $\begin{array}{l}\text { 1Model } \\
\text { 1Strip } \\
\text { 2Strip } \\
\text { 3Strip } \\
\text { 4Strip } \\
\text { 5Strip }\end{array}$ & $\begin{array}{l}0.003 \\
0.011 \\
0.011 \\
0.011 \\
0.010 \\
0.010\end{array}$ & $\begin{array}{l}0.005 \\
0.009 \\
0.009 \\
0.009 \\
0.008 \\
0.009\end{array}$ & $\begin{array}{l}0.005 \\
0.012 \\
0.011 \\
0.012 \\
0.011 \\
0.012\end{array}$ & $\begin{array}{l}0.043 \\
0.028 \\
0.025 \\
0.022 \\
0.021 \\
0.022\end{array}$ & $\begin{array}{l}0.050 \\
0.029 \\
0.025 \\
0.024 \\
0.022 \\
0.022\end{array}$ & $\begin{array}{l}0.088 \\
0.053 \\
0.048 \\
0.046 \\
0.043 \\
0.044\end{array}$ \\
\hline
\end{tabular}

* Values at Photo Scale 1:1

From Tables 4 and 5 the following conclusions can be drawn:

- The derived mathematical models are suitable for self calibration block adjustment for a block of photographs of any size.

- Adding constraints improves the accuracy of the obtained results.

- Lens distortion errors have significant effect on the accuracy of block adjustment especially for Z coordinates determination.

- The results of self calibration block adjustment using the coplanarity equations with constraints are slightly better than the results for using collinearity equations. 


\section{DISCUSSION \& CONCLUSIONS}

- Coplanarity equations are applicable to simultaneous and self calibration block adjustment for blocks of photographs of any size.

- The coplanarity equations have significant effect on compensating the lens distortion errors rather than collinearity equations.

- The accuracy of the results of self calibration block adjustment using coplanarity equations is slightly better than using collinearity equations.

- Compared to the collinearity equations, the coplanarity equations solution has the following disadvantages:

- Not suitable for single photograph

- Very complex differential coefficients.

- Least squares method solution requires the inverting of two matrices, $Q_{e}$ (Equation (15)) to form the normal equations and $\mathrm{N}$ (Equation (14)) to solve for the unknowns. A direct method of computing and inverting such large matrices is not practical due to both the excessive amount of computer time and memory required and also because of the rounding off of errors in machine calculations. For this reason, it is recommended that researches should be continued to study the characteristic patterned forms of these matrices and development of efficient methods for solving the system of normal equations.

- This paper shows the necessity for the mathematical photogrammetric data for testing the photogrammetric methods and softwares.

Table 5. The Results of Self Calibration Block Adjustment (Case of Random and Lens Distortion Errors)

\begin{tabular}{|c|c|c|c|c|c|c|c|}
\hline \multirow{3}{*}{ 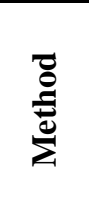 } & \multirow{3}{*}{$\begin{array}{l}\text { Block } \\
\text { Title }\end{array}$} & \multicolumn{6}{|c|}{ RMSE Values for Ground Coordinates $(\mu m)^{*}$} \\
\hline & & \multicolumn{3}{|c|}{ Control Points } & \multicolumn{3}{|c|}{ Check Points } \\
\hline & & $\mathbf{X}$ & $\mathbf{Y}$ & $\mathbf{Z}$ & $\mathbf{X}$ & $\mathbf{Y}$ & $\mathbf{Z}$ \\
\hline 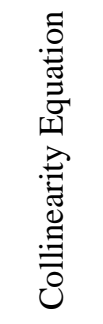 & $\begin{array}{l}\text { 1Model } \\
\text { 1Strip } \\
\text { 2Strip } \\
\text { 3Strip } \\
\text { 4Strip } \\
\text { 5Strip }\end{array}$ & $\begin{array}{l}1.88 \\
1.78 \\
1.43 \\
1.89 \\
1.85 \\
1.76\end{array}$ & $\begin{array}{l}0.88 \\
1.44 \\
2.49 \\
2.32 \\
1.77 \\
2.25\end{array}$ & $\begin{array}{l}3.55 \\
2.37 \\
2.90 \\
2.86 \\
2.40 \\
2.40\end{array}$ & $\begin{array}{l}4.26 \\
5.02 \\
2.81 \\
2.36 \\
2.65 \\
2.51\end{array}$ & $\begin{array}{l}5.62 \\
5.26 \\
3.66 \\
3.50 \\
2.94 \\
3.00\end{array}$ & $\begin{array}{l}8.90 \\
7.78 \\
6.30 \\
6.22 \\
5.01 \\
5.72\end{array}$ \\
\hline 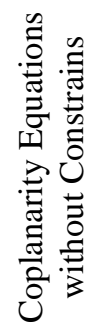 & $\begin{array}{l}\text { 1Model } \\
\text { 1Strip } \\
\text { 2Strip } \\
\text { 3Strip } \\
\text { 4Strip } \\
\text { 5Strip }\end{array}$ & $\begin{array}{l}-- \\
-- \\
-- \\
-- \\
-- \\
--\end{array}$ & $\begin{array}{l}-- \\
-- \\
-- \\
-- \\
-- \\
--\end{array}$ & $\begin{array}{l}-- \\
-- \\
-- \\
-- \\
-- \\
--\end{array}$ & $\begin{array}{l}4.40 \\
5.11 \\
3.08 \\
2.28 \\
2.60 \\
2.61\end{array}$ & $\begin{array}{l}5.44 \\
5.50 \\
3.60 \\
3.33 \\
2.91 \\
3.07\end{array}$ & $\begin{array}{l}8.97 \\
7.90 \\
6.42 \\
6.42 \\
5.13 \\
6.17\end{array}$ \\
\hline 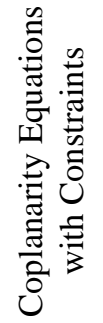 & $\begin{array}{l}\text { 1Model } \\
\text { 1Strip } \\
\text { 2Strip } \\
\text { 3Strip } \\
\text { 4Strip } \\
\text { 5Strip }\end{array}$ & $\begin{array}{l}1.75 \\
1.70 \\
1.37 \\
1.70 \\
1.75 \\
1.63\end{array}$ & $\begin{array}{l}0.86 \\
1.37 \\
2.30 \\
2.15 \\
1.71 \\
2.10\end{array}$ & $\begin{array}{l}3.32 \\
1.90 \\
2.79 \\
2.68 \\
2.27 \\
2.26\end{array}$ & $\begin{array}{l}4.10 \\
4.78 \\
2.73 \\
2.20 \\
2.49 \\
2.36\end{array}$ & $\begin{array}{l}5.20 \\
4.89 \\
3.51 \\
3.26 \\
2.81 \\
2.80\end{array}$ & $\begin{array}{l}8.38 \\
7.48 \\
6.10 \\
5.90 \\
4.74 \\
5.40\end{array}$ \\
\hline
\end{tabular}

* Values at Photo Scale 1:1 
International Journal of Advances in Scientific Research and Engineering (ijasre), Vol 7 (2), February -2021

\section{APPENDIX ERROR GENERATOR FORMULATION}

Almost all algorithms for generating normally distributed random numbers are based on transformation of uniform distribution [13],[14].

There are different functions for computing uniform distribution. The rand() function suggested by Herbert Schildt [16] and supplied by most $\mathrm{C}$ libraries is the one shown below.

$$
\left.\begin{array}{l}
S E E D=\left(1103515245^{*} S E E D+12345\right) \bmod 2^{b} \\
x_{i}=S E E D / 2^{b}
\end{array}\right\}
$$

where SEED is a value which gets updated at each iteration, $\mathrm{b}$ is the word size of computer i.e. number of bits, and $x_{i}$ is the random number returned at each iteration.

The generated sequence of $x_{i}$ will be uniformly distributed between 0 and 1 . The mean of the distribution is $1 / 2$ and the variance is $1 / 12$.

For normally distributed error $\left(\varepsilon_{j}\right)$ required, the following approximation [5] may be used:

$$
\varepsilon_{j}=\sigma\left(\sum_{i=1}^{12} x_{i}-6\right)+\mu
$$

The $\varepsilon_{j}$ are then normally distributed about the mean value $\mu$ and their standard deviation is $\sigma$.

\section{REFERENCES}

[1] S. Ghosh, Fundamentals of Computational Photogrammetry, Concept Publishing Company, New Delhi, India, 2005.

[2] P. Wolf, B. Dewitt and B. Wilkinson, Elements of Photogrammetry with Applications in GIS, Fourth Edition. McGraw-Hill Education, 2014.

[3] K. El-Ashmawy "Photogrammetric block adjustment without control points", Geodesy and cartography. 44. 6-13. https://doi.org/10.3846/gac.2018.880, 2018.

[4] K. El-Ashmawy "A Cost-Effective Photogrammetric System for Engineering Applications", Ph.D. Thesis, Department of Civil Engineering, University of Roorkee, Roorkee, India, 1999.

[5] K. El-Ashmawy, "Using direct linear transformation (DLT) method for aerial photogrammetry applications", Geodesy and cartography. 44. 71-79. https://doi.org/10.3846/gac.2018.1629, 2018

[6] Y. Zhang, and M. Zheng, "BUNDLE BLOCK ADJUSTMENT WITH SELF-CALIBRATION OF LONG ORBIT CBERS02B IMAGERY", International Archives of the Photogrammetry, Remote Sensing and Spatial Information Sciences, Volume XXXIX-B1, XXII ISPRS Congress, 25 August - 01 September 2012, Melbourne, Australia, 2012

[7] Y. Bo, "Accuracy Validation of Large-scale Block Adjustment without Control of ZY3 Images over China", ISPRS Annals of the Photogrammetry, Remote Sensing and Spatial Information Sciences, Volume III-1, 2016

[8] K. Di, Y. Liu, B. Liu, M. Peng, and W. Hu, "A Self-Calibration Bundle Adjustment Method for Photogrammetric Processing of Chang E-2 Stereo Lunar Imagery", IEEE TRANSACTIONS ON GEOSCIENCE AND REMOTE SENSING, VOL. 52, NO. 9, SEPTEMBER 2014 
International Journal of Advances in Scientific Research and Engineering (ijasre), Vol 7 (2), February -2021

[9] R. Rostom, Patterns of Aerial Triangulation by Independent Models, Department of Geospatial and Space Technology, University of Nairobi, Kenya, 1992.

[10] S. Ghosh, Phototriangulation, Lexington Books; Lexington, Mass, 1975.

[11] E. Mikhail, S. James, and J. Chris, Introduction to Mordern Photogrammetry, John Wiley \& Sons,Inc.U.S.A, 2001

[12] S. Joag, An Introduction to Vectors, Vector Operators and Vector Analysis, Cambridge University Press, Daryaganj, Delhi, India, 2016.

[13] C. GHILANI and P. WOLF, ADJUSTMENT COMPUTATIONS: Spatial Data Analysis, 6th Edition. JOHN WILEY \& SONS, IN., 2017

[14] M. Mikhail, Observations and Least squares, Thomas Y. Crowel Company, Inc., 1983.

[15] D. Malik, Data Structures Using C++, Second Edittion. Cengage Learing, Inc., USA, 2010.

[16]H. Schildt, Turbo C/C++: The Complete Reference, Second Edition. McGraw-Hill,Inc., USA,1992.

[17] K. Gregory, Special Edition Using Visual C++ 6, Que, USA, 1998. 